\title{
Applying Automated and Robotic Means in Construction as a Factor for Providing Constructive Safety of Buildings and Structures
}

\author{
Denis Shutin ${ }^{1, *}$, Aleksander Malakhov ${ }^{2}$ and Kirill Marfin ${ }^{3}$ \\ ${ }^{1}$ Department of Mechatronics, Mechanics and Robotics, OSU named after I.S. Turgenev, 95 \\ Komsomolskaya street, Oryol, 302000, Russian Federation \\ ${ }^{2}$ Department of Unique Buildings and Structures, Southwest State University, 9450 Let Oktyabrya \\ street, Kursk, 305040, Russian Federation \\ ${ }^{3}$ Department of Building Constructions and Materials, OSU named after I.S. Turgenev, 95 \\ Komsomolskaya street, Oryol, 302000, Russian Federation
}

\begin{abstract}
The paper considers introduction of automated and robotic means in the construction industry, in particular for building from block materials, and its possible impact at improvement of building process quality and reliability of buildings and structures. Currently, manual labor is used for most operations during the block-laying process. Unstable quality of manual labor causes numerous defects that are detected during the technical inspection and monitoring of buildings and structures. Simultaneously, the current technological level is enough high for developing automated and robotic means for main operations in the considered process. At the same time there is the issue of ensuring the quality of the operations performed by such devices. The most significant limiting factor is measurement means, like sensors and algorithms used for processing the data obtained from the sensors. Thus, the basic requirements to the measurement means based on the current standards have been formulated during this research. Applying the automated and robotic means meeting these requirements will allow improve the block-laying process qualitatively, both in terms of its performance and in terms of reliability of the resulting constructions.
\end{abstract}

\section{Introduction}

Automation is one of the main technological challenges in modern construction. Automatic systems are already widely used in many industries and the share of automated productions continues growing. At the same time, construction is rather conservative industry. In average, new technologies are introduced in construction rarely than in many other industries. Development and introduction of new technologies connected with automation in construction are often expensive and time-consuming, so the share of manual labor is still very high. Besides, developing automated solutions for construction is often a

\footnotetext{
*Corresponding author: rover.ru@gmail.com
} 
sophisticated task, and cost-effective technologies may be obtained only while using the most modern achievements in sensors, drives, control systems and algorithms.

Construction of blocks (mostly, bricks) is one of the most perspective technologies in the considered industry to be automated. Brick-laying is the most labor-consuming and expensive technologies that is widely used in modern construction. The principles, potential and the basic capabilities for the application of robotic systems for automation of the specified process are shown in $[1,2]$.

At the same time, the results of technical inspection of buildings with different functions [3-6] made of blocks materials indicates that using automation and robots during building such constructions is a real opportunity to improve the quality and reduce building time. The strict adherence to the blocks laying technology will allow also reduce the number of defects appearing both during the building period and during the operational period. Reducing the number of defects is a necessary factor of the constructive safety that is one of the main problems in the industry $[7,8]$.

It should be noted that the use of automation mean scan reduce the number of defects directly related to the process of laying blocks. Reducing the number of defects connected with the physical and chemical properties of materials, the operation regime cannot be solved by automation.

\section{Typical defects in buildings made from blocks}

The main types of defects found during surveys in living and public buildings made from blocks are deviation of masonry levels from vertical and horizontal planes [9]. Such defects lead to appearance of a stress-strain state that is not typical for constructions made of blocks. In its turn, it leads to reduction in strength. The frequent result of such errors is appearance and further increase of cracks. Cracks often appear in the corners and may lead to compete destruction of the building or its parts. The examples of such cracks in public buildings are shown in Fig. 1.
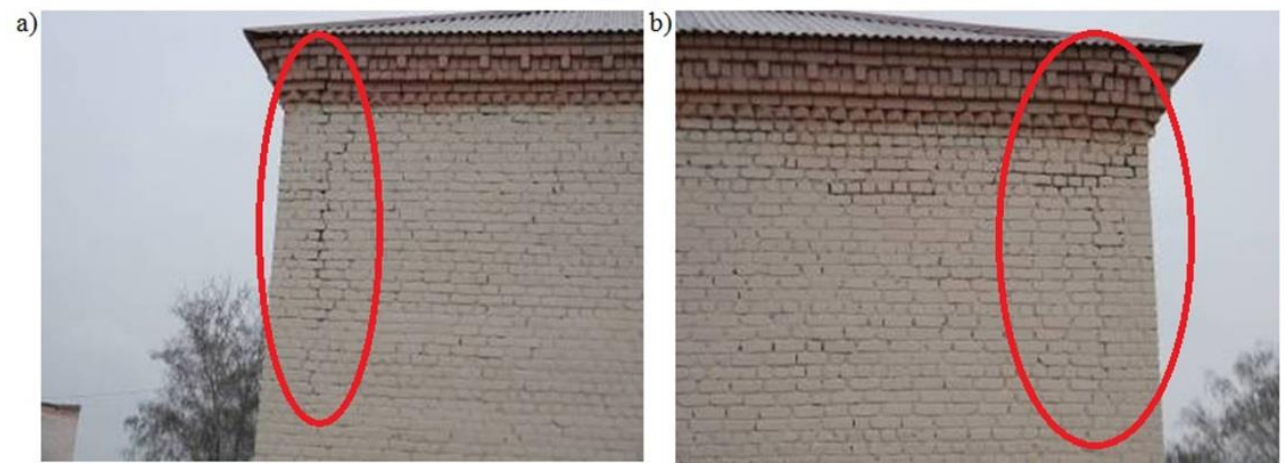

Fig. 1.Defects in the construction made of bricks in the public building caused by low quality of brick work

According to [8], the maximum permissible deviations of geometrical parameters of constructions made of blocks are:

deviations of surfaces and corners from the vertical direction:

- For one floor $(3 \mathrm{~m})-10 \mathrm{~mm}$

- For a building higher than 2 floors $-30 \mathrm{~mm}$

deviations of rows from the vertical direction for each $10 \mathrm{~m}$ of the wall length: $15 \mathrm{~mm}$.

The exact values of the mentioned parameter vary in different countries within certain limits, but in general they show physical features of block constructions. 
Low quality of brick work also causes negative in fluence on thermal technical characteristics of the building. It is often connected within crease in the amount of grout between the blocks while grout is the main factor of heat losses. Labor costs for finishing work also increase when there are geometrical defects in the constructions made of blocks. Eliminating such defects in finished buildings is an expensive, complicated and even not always possible operation. So it is quite reasonable to provide the required quality of brickwork during the building process. It is not guaranteed when using manual labor but automated means provide always stable parameters of the obtained results.

Another typical problems in constructions made of block that experts deal with during technical surveys are mostly often caused by dynamic impacts (e.g. operation of cranes) [10] and aggressive environmental conditions during the building process [11]. In such buildings compliance of all levels in brick constructions is strictly required. It is due to the fact that according to the building standards in Russian Federation the height of such buildings is limited by 12 meters, and bricks bond and reinforcing bands are not required and, as a consequence, in most cases are not implemented. So, global geometry defects in such constructions lead to emergency situations with high probability.

a)

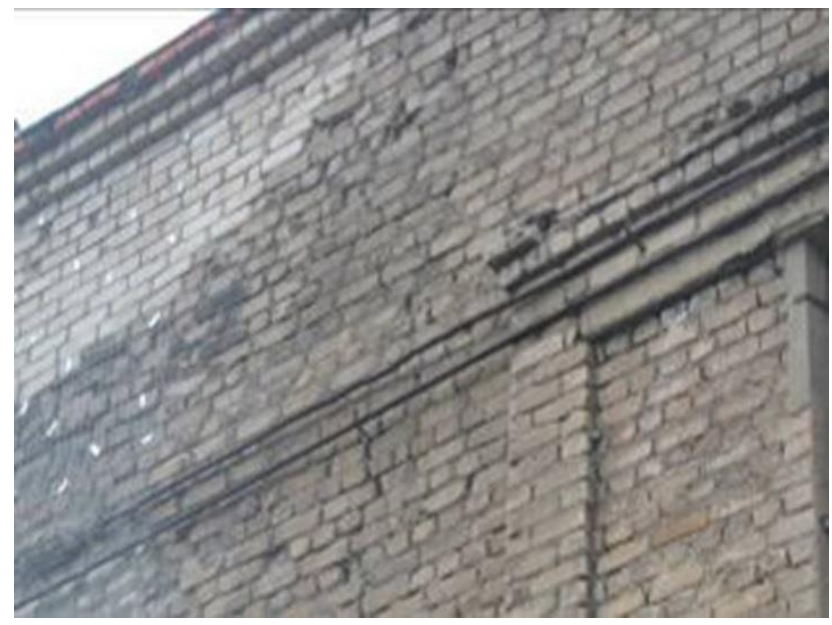

b)

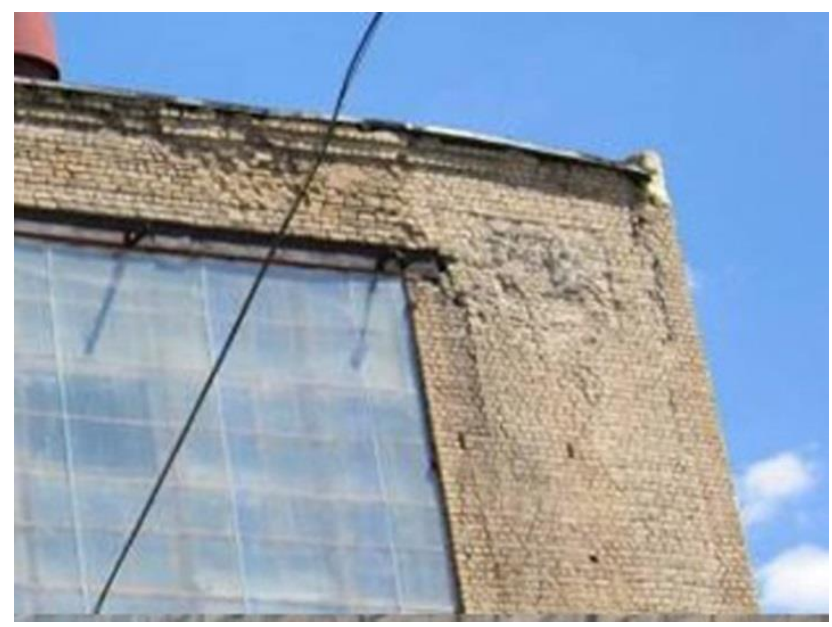

Fig. 2.Defects in the construction made of bricks in industry buildings caused by low quality of brick work 
Under the dynamic loads the construction made of blocks operates with very high mechanical stresses. Such operation regimes accelerates appearance of cracks. Aggressive environmental conditions cause erosion that reduced the section of the construction. In common, the mentioned factors and insufficient quality of brickwork are typical reasons of accidents with buildings made of blocks.

\section{Reducing the possibility of defects due to using automated and robotic means}

The main tasks in automated and robotic systems for laying blocks are transportation the block to the laying area and positioning it according to the masonry plan. Accuracy of its positioning determines accuracy of the built construction in general. When using mobile robotic systems described in $[1,2]$, correlating the coordinate systems of the robot and the building is implemented at first, and then the block is positioned directly at its final place. Direct controlling the geometry of the construction at its full size is rather complicated due to the fact that the size of building is much bigger than the size of the automated system (robot). So, during the bricklaying process only a limited area of the construction is used as the reference base for local aligning of the formed construction. Correspondence of its geometry to the requirements in general should be controlled by special methods. Such methods may use either external measurement facilities, like in [12] or internal facilities with partial extrapolation of the measured data. The first way requires expensive hardware, while the second one may be much cheaper but requiring advanced mathematical apparatus for providing the necessary accuracy of the obtained results. Such way has been chosen in the developed robotic system $[1,2]$. Positioning of the block in is implemented using a camera with machine vision as $\mathrm{s}$ sensor. Such approach provides higher flexibility than conventional sensors.

The accuracy of positioning of the laid block is determined by the least accuracy among the components of the block-laying system. In the considered system such components are the manipulator and the sensor system. The typical accuracy of positioning of modern mechanical manipulators based on non-precise ball-screw transmission and step-motor drive is $0.01-0.02 \mathrm{~mm}$. The modern machine vision systems provide an object position detection up to $0.14 \%$. Taking into account the size and construction of the block-laying robot and the typical block maximal size of $0.3 \mathrm{~m}$, the order of accuracy of measuring the block's position that can be obtained is $0.5 \mathrm{~mm}$ [13]. Taking into consideration the allowable geometry deviations mentioned above it is possible to state, that there are no sufficient obstacles to providing the accuracy of an automated system much better than accuracy of a human. With that, solution of this task requires development of an adequate measuring scheme using machine vision systems. Also, since the main geometrical parameters that determine the quality of the construction relate to its global dimensions, it is necessary to control the global accuracy in addition to the accuracy of positioning each block separately, the following requirements to the sensor system of a block-laying robot can be formulated:

- The accuracy of positioning of a block in the row not less than $1 \mathrm{~mm}$

- Possibility of determining the deviation of the construction's form in the horizontal direction not less than $1.5 \mathrm{~mm}$

- Possibility of determining the deviation of the construction's form in the vertical direction not less than $3 \mathrm{~mm}$

Development of the sensor system that meets these requirements will allow provide the level of construction safety of buildings corresponding to the current standards in construction. 


\section{Discussions}

The use of automated and robotic means for building from block materials can be considered not only as the means for reducing the cost and increasing labor productivity [14], but also as the mean for improving reliability of buildings by reducing the number of defects and maintaining their service life at the required level. The practice of technical inspections of different purposes buildings made of blocks shows that the problems of quality of building are actual, so development and introduction of automated and robotic means for building from block materials may be a significant improvement of the technological stack in the construction industry. Modern technologies in robotics, mechatronics, sensors and IT provide enough means for development solutions that would meet the requirements relating to accuracy and productivity of the corresponding technological processes.

The study is implemented with support of the Innovation Promotion Fund, project No. 1560GU/2017 "Development of a mobile robotic complex for building from block materials".

\section{References}

1. N.V. Fedorova, A.V. Malakhov, D.V. Shutin, Technol. of textile Ind., 367, 226-232 (2017)

2. A.V. Malakhov, D.V. Shutin, Proceedings of BSTU named after V.G. Shukhov, 8, 57-59 (2017)

3. V.I. Rimshin, Survey and Testing of Buildings and Construction, (2004)

4. A.N. Dobromyslov, Evaluation of Reliability of Buildings and Structures by Their Appearance (2008)

5. GOST 31937-2011. Buildings and Structures. The Rules for Inspection and Monitoring of Technical Conditions (2010)

6. GOST 26629-85. Buildings and Structures. Method of Thermo-Vision Control of Enclosing Structures Thermal Insulation Quality (2010)

7. Federal law of Russian Federation from 30.12.2009 N384-FZ "Technical regulations on the safety of buildings and structures", Available via SPS KonsultantPlus. http://www.consultant.ru/document/cons_doc_LAW_95720/(2017)

8. FAU “FCS” SP 70.13330.2011 “Supporting and Protecting Structures" (2013)

9. GOST $R$ 54257-2014. Reliability of Building Structures and Foundations. Basic Provisions and Requirements (2014)

10.V.M. Bondarenko, D.G. Suvorkin, Reinforced Concrete and Stone Structures (1987)

11. V.M. Bondarenko, V.I. Rimshin, Dissipative Theory of Strength Resistance of Reinforced Concrete (2015)

12. A.V. Malakhov, D.V. Shutin, Integration, Partnership and Innovation in Building Science and Education: Proceedings of the International Scientific Conference, 270274 (2016)

13. Fastbrick Robotics Ltd. Official Website, Available via Google Chrome, https://www.fbr.com.au/ (2018)

14. D. Wu, T. Chen, A. Li, Sensors, 16(9), 1388 (2016) 